\title{
PENANGGULANGAN KEMACETAN MENGGUNAKAN METODE CLUSTER BASED PADA JARINGAN MOBILE ADHOC
}

\author{
Firly Firman Islam ${ }^{2}$, Dinar H S Wahyuni ${ }^{1}$, Basitha F. Hidayatulail ${ }^{1}$ \\ ${ }^{1}$ Jurusan Teknik Elektronika UNMER Malang \\ ${ }^{2}$ Departemen Optik dan Hidrolik Lembaga Pengkajian Teknologi TNI-AD \\ Email : Firlyfirisllam@gmail.com
}

\begin{abstract}
Abstrak
Permasalahan kemacetan lalu lintas di daerah perkotaan merupakan hal yang sudah umum kita jumpai. penelitian ini dimodelkan dengan simulasi network simulator 2 dengan menggunakan metode cluster bades dimana setiap kumpulan node akan diklasifikasikan menjadi 4 cluster, simulasi ini menggunakan head cluster guna mengelompokkan node-node pada setiap clustemya. Hasilnya adalah cluster yang melebi ketentuan batas jumlah node akan dipindahkan ke arah kiri.
\end{abstract}

Kata Kunci: Kemacetan,Metode Cluster Based, Network Simulator 2

\section{Pendahuluan}

Indonesia ialah negara dengan banyak kepulauan serta letak geografis yang berbeda beda merupakan negara yang terus berkembang. Seperti negara berkembang lainya yang memiliki permasalahan lalu lintas, dimana lalu lintas merupakan sarana untuk bergerak dari satu tempat ke tempat yang lainnya, jika jalur ini terganggu atau terjadi kemacetan maka mobilitas masyarakat juga terganggu[1]. Gangguan ini akan menimbulkan dapat negative seperti kerugian finansial baik secara individu maupun kelompok.

Bertambahnya jumlah penduduk, kendaraan pibadi dan tidak sadarnya masyarakat akan pentingnya menggunakan angkutan transportasi masalah merupakan hal yang menyebabkan terjadinya kemacetan lalu lintas[2][3]. Kejadian ini merupakan salah satu kejadian yang sudah biasa terlihat pada saat pagi, sore bahkan malam hari yang umumnya terjadi di kota-kota besar Indonesia.

Penelitian dari pergerakan kendaraan bermotor yang ada bercampur dengan kendaraan non motor antara lain becak dan gerobak, bergeraknya tidak searah dengan arah lalu lintas kendaraan bermotor. Hal ini didukung dengan tidak disiplinnya pejalan kaki serta kendaraan yang parkir sembarangan dan pedagang kaki lima juga yang menambah semakin macetnya keadaan lalu lintas.

Penelitian dari [4]menjelaskan mengenai Sebuah konsep nirkabel memungkinkan untuk inter vehicle dan vehicle to roadside, konsep yang seperti ini merupakan subset dari mobile AdHoc Network yaitu Vahicular Ad-Hoc (VANET). Tujuan penggunaan VANET merupakan penyedia aplikasi transportasi guna mendukung kenyamanan serta keamanan bagi pengendara[5][6].

Berdasarkan penjelasan paragraph diatas maka diperlukan mekanisme penanggulangan permasalahan kemacetan lalu lintas. Permasalahan tersebut diselesaikan dengan mensimulasikan menggunakan mobile ad hoc network cluster based key managenen. Simulasi ini akan menghitung beberapa traffic yang ada dan secara otomatis melakukan pengaturan secara otomatis[7].

\section{Metode penelitian}

Dalam penelitian ini dimodelkan dengan menggunakan simulasi, cara yang digunakan adalah membandingkan dua scenario yang berbeda. antara lain scenario dengan 
menggunakan 23 node dan 44 node, scenario yang terbaiklah yang nantinya akan digunakan sebagai acuan dalam pengambilan keputusan[8][9]. Karakteristik node dan pemodelan energy diperlihatkan pada Table 3.1 dan 3.2 sedangkan Gambar 3.1 Diagram Alir Skema Cluster Based Key Management dan Gambar 3.2 Diagram Alir Rancangan Penelitian.

Tabel 2.1 Karakteristik Node

\begin{tabular}{lc}
\hline \multicolumn{1}{c}{ Parameter } & Nilai \\
\hline Kecepatan Node & $20-25(\mathrm{~m} / \mathrm{s})$ \\
Frekuensi & VHF \\
Antena & Omni Directional \\
Routing Protocol & AODV \\
Model Propagasi & TwoRay \\
Jumlah Node & $23,44,65$ Node \\
Jangkauan Radio & $\leq 250 \mathrm{~m}$ \\
Ukuran Area & $1000 \times 1000(\mathrm{~m})$ \\
Wak u Simulasi & $160 \mathrm{~s}$ \\
MAC & 802.11 \\
Su ber Traffic & CBR \\
Ukuran Paket & 512 byte
\end{tabular}

Tabel 2.2 Pemodelan Energi

\begin{tabular}{lc}
\hline \multicolumn{1}{c}{ Satuan } & Joule \\
\hline Energy awal & 2500 \\
Besar energy per paket & 1,239 \\
Besar energy routing & 2,726
\end{tabular}

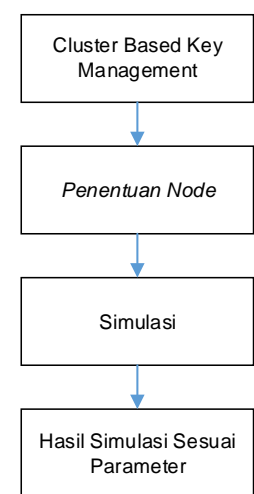

Gambar 2.1 Diagram Alir Skema Cluster Based Key Management

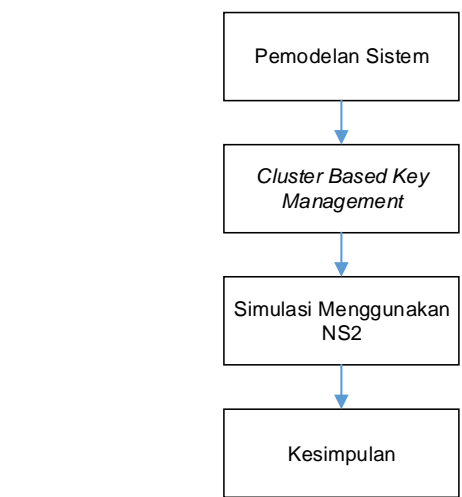

Gambar 2.2 Diagram Alir Rancangan Penelitian

\section{Hasil dan Analisis}

Setelah perancangan dan pembuatan simulai diselesaikan maka dilakukan pengujian system untuk mengetahui simulasi berjalan seperti yang diharapkan. pengujian ang dilakukan antara lain:

\subsection{Parameter Efficienc}

Tujuan dari pengujian ini adalah guna mengetahui banyaknya energy yang terpakai dalam setiap scenario, seperti terlihat pada Tabel 4.1.

\begin{tabular}{ccc}
\multicolumn{3}{c}{ Tabel 3.1 Efisiensi Energi } \\
\hline Skenario & $\begin{array}{c}\text { Energi } \\
(\mathrm{J})\end{array}$ & $\begin{array}{c}\text { Efisiensi } \\
(\%)\end{array}$ \\
\hline I & 703 & 28,12 \\
II & 1012 & 40,48 \\
III & 1009 & 40,36 \\
IV & 1458 & 58,32 \\
V & 1900 & 76
\end{tabular}

\section{Efisiensi (\%)}

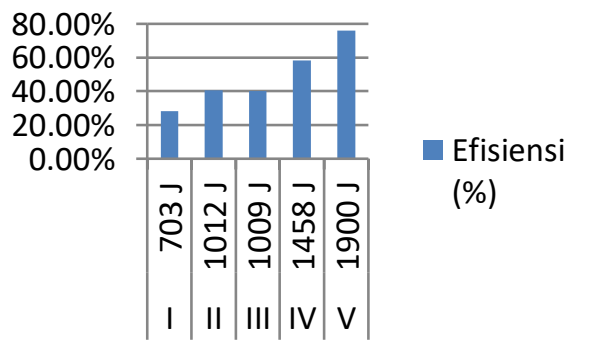

Gambar 3.1 Grafik Efisiensi Energi 


\subsection{Parameter Scalability}

Tujuan pengujian adalah mengukur kemampuan sebuah system untuk menangani perubahan jumah node dalam jaringan. Untuk mengevaluasi scalability dibandingkan dari tiga nilai parameter (Routing Overhead, Packet Loss dan Energy)[10][11].

Tabel 3.2 Efisiensi Scalability

\begin{tabular}{ccccc}
\hline Skenario & F1 & F 2 & $\begin{array}{c}\text { F 3 } \\
(\mathrm{J})\end{array}$ & UX \\
\hline I & 948260 & 88 & 703 & 379479,8 \\
II & 689725 & 61 & 1012 & 276116.8 \\
III & 685848 & 60 & 1009 & 274565 \\
IV & 991368 & 83 & 1458 & 396872 \\
V & 1838608 & 171 & 1900 & 735891.6
\end{tabular}

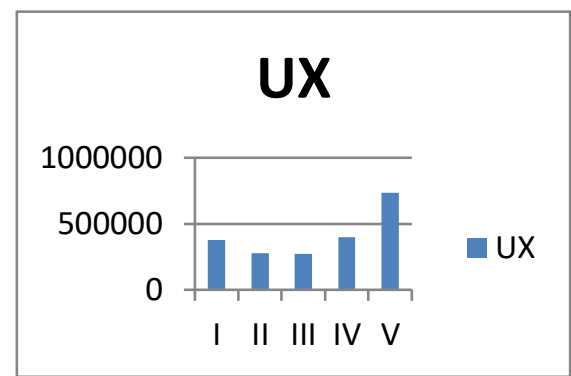

Gambar 3.2 Grafik Scalability

\subsection{Pengamatan Terhadap Simulasi}

simulasi ini memiliki tiga posisi, antara lain posisi sebelum node dibelokkan, node saat dibelokkan dan node setelah dibelokkan[12][13].
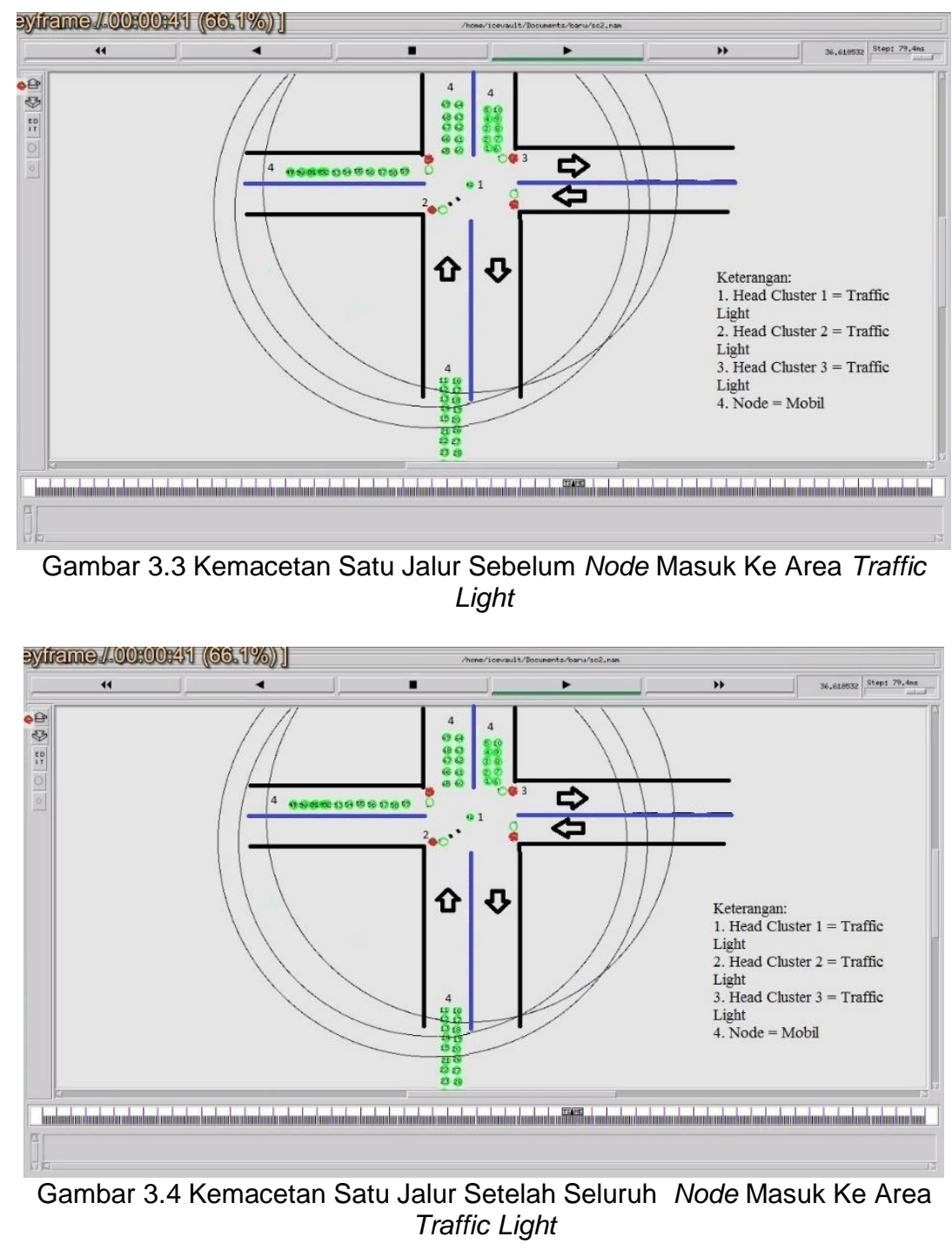


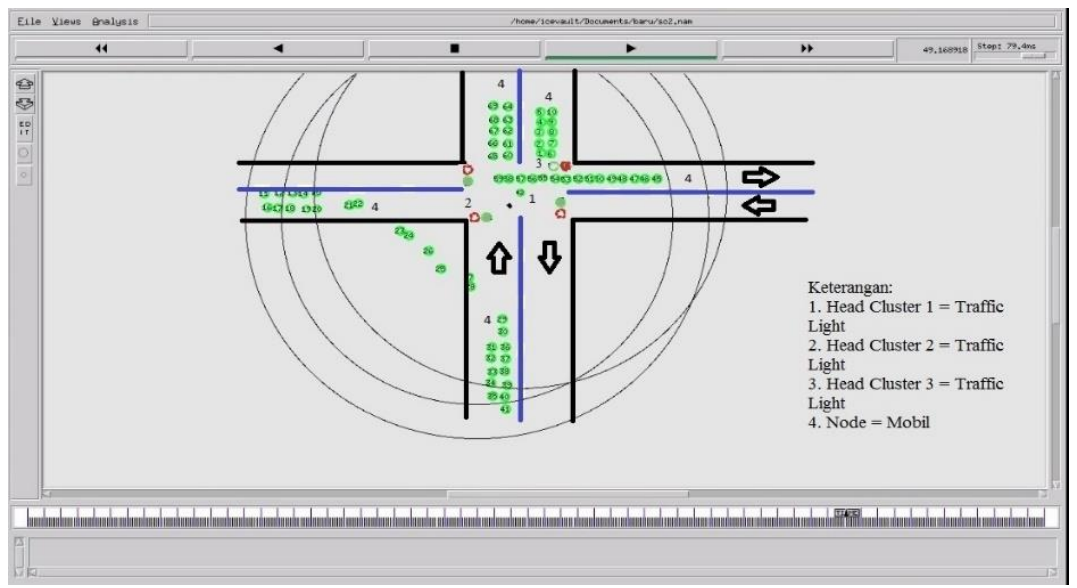

Gambar 3.5 Kemacetan Satu Jalur Saat Node Dibelokkan

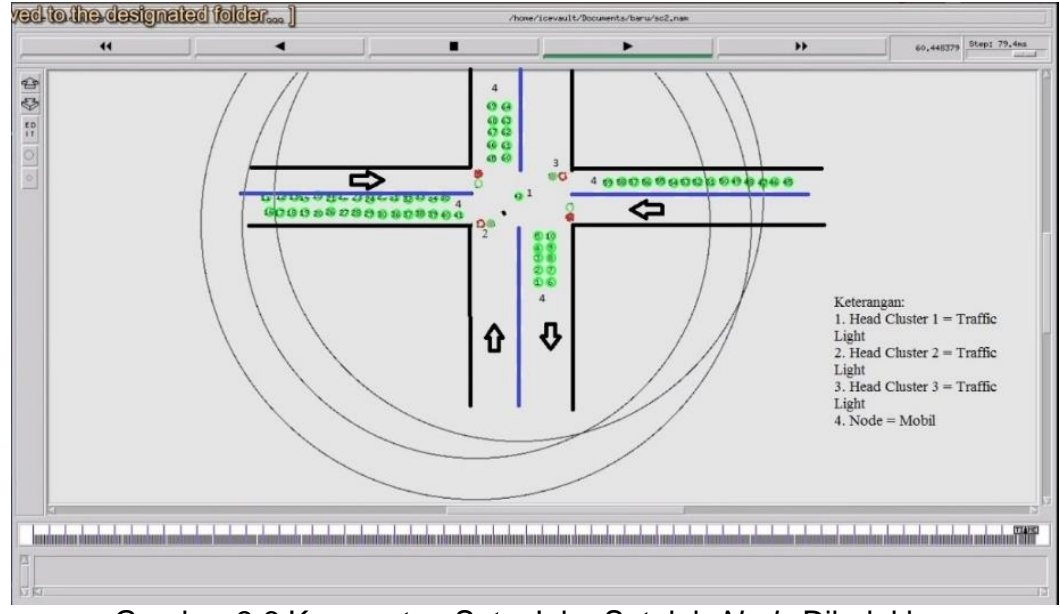

Gambar 3.6 Kemacetan Satu Jalur Setelah Node Dibelokkan

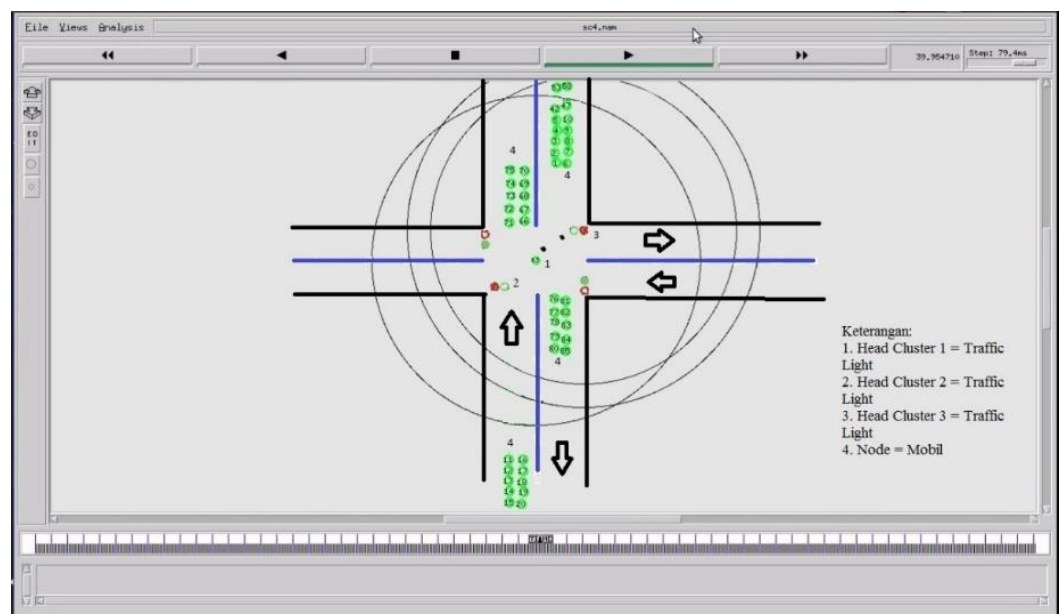

Gambar 3.7 Kemacetan Dua Jalur Sebelum Node Masuk Ke Area Traffic Light 


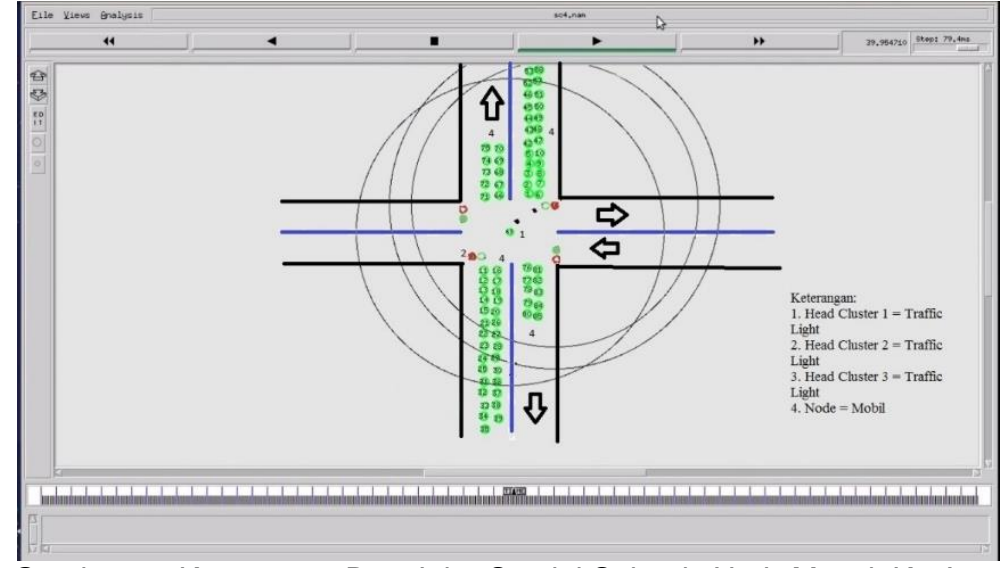

Gambar 38 Kemacetan Dua Jalur Setelaj Seluruh Node Masuk Ke Area Traffic Light

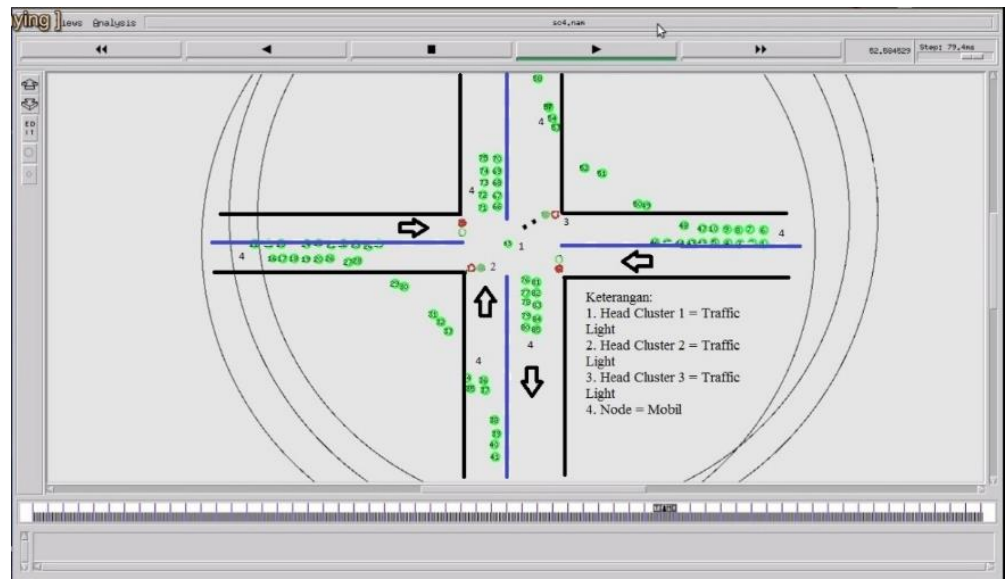

Gambar3.9 Kemacetan Dua Jalur Saat Node Dibelokkan

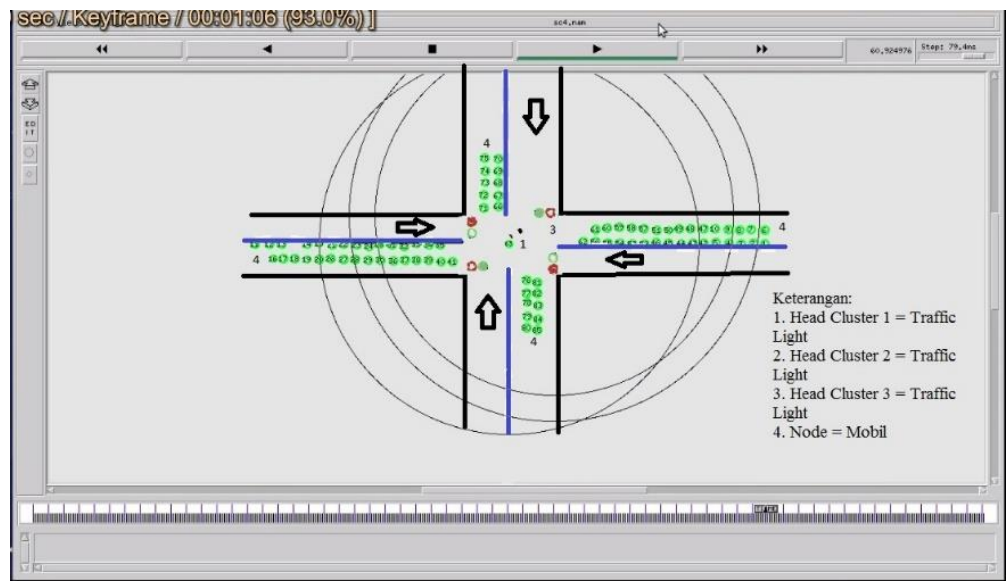

Gaambar 3.10 Kemacetan Dua Jalur Setelah Node Dibelokkan

Dari hasil pengamatan setiap simulassi, posisi node diasumsikan sebagai mobil dengan node disetiap clustemya melebihi kuota, dalam situasi ini ditentukan jika melebihi kuota 30 node disetiap jalurnya maka tugas head cluster mendeteksi dan membelokkan ke kiri.[14][15]

\section{Kesimpulan}

Dari hasil pengujian simulasi diatas, ada beberapa hal yang dapar disimpulkan, antara lain:

a. Simulasi ini dapat mengatur traffic light dengan head cluster sebagai pengaturnya. 
b. Simulasi ini dapat mendeteksi banyaknya node di tiap cluster.

c. Simulasi ini dapat mengatur kemacetan 2 arah dengan jumlah node yang digunakan 23,44 , dan 65.

d. Dengan menggunakan routing AODV, node dapat diatur dengan mudah dan mendeteksi berapa banyak node ditiap cluster nya.

e. Metode cluster based key management, berfungsi untuk mengclusterkan node, dengan begitu setiap cluster dapat diatur dan dihitung berapa banyak node yang ada dalam cluster tersebut.

f. Dalam simulasi ini jika terjadi penumpukan node di salah satu cluster, maka akan diasumsikan cluster tersebut penuh atau macet. Dengan begitu node akan dibelokkan kea rah kiri untuk mengurangi penumpukan atau kemacetan dalam cluster tersebut.

g. Perbandingan dengan menggunakan parameter Efficiency, Energy yang di konsumsi jika menggunakan metode cluster based jauh lebih sedikit dibandingkan dengan tidak menggunakan metode tersebut.

h. Nilai scalability yang didapat jika tidak menggunakan metode cluster based key management sangat besar, dikarenakan energi yang dikonsumsi, packet loss dan routing overhead juga tinggi.

\section{References}

[1] M. S. A. G. dan J. H. Gea, "Analisis Kinerja Ruas Jalan Akibat Parkir Pada Badan Jalan ( Studi Kasus : Pasar dan Pertokoan di Jalan Besar Delitua )," J. Tek. Sipil USU, 2012.

[2] I. A. Rahardjo, R. Anggoro, and F. X. Arunanto, "Studi Kinerja 802.11P pada Protokol Ad Hoc On-Demand Distance Vector (AODV) di Lingkungan Vehicular Ad Hoc Network (VANET) Menggunakan Network Simulator 2 (NS-2)," J. Tek. ITS, 2017.

[3] R. Yuwono, I. Mujahidin, A. Mustofa, and Aisah, "Rectifier using UFO microstrip antenna as electromagnetic energy harvester," Adv. Sci. Lett., 2015.

[4] I. A. Rahardjo, R. Anggoro, and F. . Arunanto, "Studi Kinerja 802.11P pada Protokol," Jur. Tek. Inform. Fak. Teknol. Informasi, Inst. Teknol. Sepuluh Nop., vol. 6, no. 1, pp. 1-6, 2017.

[5] Encyclopedia of Complexity and Systems Science. 2019.

[6] I. Mujahidin, R. Yuwono, and A. Mustofa, "Rancang Bangun Rectifier Antenna Mikrostrip UFO Pada Frekuensi Ultra Wideband (UWB) Sebagai Pemanen Energi Elektromagnetik," J. Mhs. TEUB, vol. 3, no. 2, 2015.

[7] B. Arthayaa, A. Sadiyokob, and C. Wiejaya, "Pengembangan Algoritma Pengenalan Bentuk dan Arah Objek pada Sistem Omnidirectional Vision Sensor," J. Tek. Elektro, 2013.

[8] C. T. Chen, "Extensions of the TOPSIS for group decision-making under fuzzy environment," Fuzzy Sets Syst., 2000.

[9] D. Avianto, "Pengenalan Pola Karakter Plat Nomor Kendaraan Menggunakan Algoritma Momentum Backpropagation Neural Network," J. Inform., 2016.

[10] D. I. Pratiwi, M. Rivai, and F. Budiman, "Rancang Bangun Deteksi Jalur Pipa Terpendam Menggunakan Mobile Robot dengan Metal Detector," J. Tek. ITS, 2017.

[11] I. Mujahidin, "Directional $1900 \mathrm{MHz}$ Square Patch Ring Slot Microstrip Antenna For WCDMA," JEEMECS (Journal Electr. Eng. Mechatron. Comput. Sci., 2019.

[12] T. Kobayashi and N. Otsu, "Image feature extraction using gradient local autocorrelations," in Lecture Notes in Computer Science (including subseries Lecture Notes in Artificial Intelligence and Lecture Notes in Bioinformatics), 2008.

[13] I. Mujahidin, S. H. Pramono, and A. Muslim, "5.5 Ghz Directional Antenna with 90 Degree Phase Difference Output," 2019.

[14] J. Nowaková and M. Pokorný, "Fuzzy linear regression analysis," in IFAC Proceedings Volumes (IFAC-PapersOnline), 2013.

[15] L. A. Zadeh, "Fuzzy logic," in Computational Complexity: Theory, Techniques, and Applications, 2013. 


\section{Daftar Riwayat Hidup}

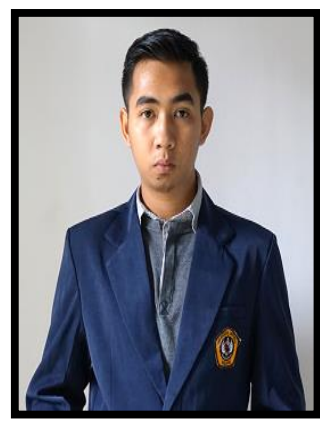

Nama

NIM

Tempat Tanggal Lahir

Agama

Alamat

Jurusan

Nomor $\mathrm{Hp}$

Email
Firly Firman Islam

14459002

Malang 06 Februari 1991

Islam

Jalan Titian II BB/15 Malang Jawa Timur

Teknik Elektro

081945964666

firlyfirmanislam@gmail.com 